\title{
US Army Corps Effects of a Nonnative, Invasive Lovegrass on Agave palmeri Distribution, Abundance, and Insect Pollinator Communities
}

\author{
by Denise L. Lindsay, ${ }^{1}$ Pamela Bailey, ${ }^{1}$ Richard F. Lance, ${ }^{1}$ Michael J. Clifford ${ }^{2}$
} Robert Delph, ${ }^{2}$ and Neil S. Cobb ${ }^{2}$

PURPOSE: This technical note is a product of the Department of Defense Legacy Resource Management Program work unit titled "Effects of invasives on the distribution of keystone desert plants on military lands." The objective of the work unit is to provide a better understanding of the impacts of invasive species on key components of ecosystems and pollinator communities. The study documented herein emphasized the integration of invasive nonnative plant invasion with other ecological processes through assessments of the spatial effects and fire dynamics of Lehmann lovegrass (Eragrostis lehmanniana) on the distribution and abundance of Palmer's agave (Agave palmeri), investigations of changes in A. palmeri pollinator community composition and diversity in the presence of high E. lehmanniana abundance, and implementation of a focused network analysis of $A$. palmeri and the plants with which it directly interacts with through shared pollinators. The purpose of this technical note is to provide information (such as key insights into important ecological relationships that foster species persistence, biodiversity, and community stability) that can be leveraged against ongoing work on pollinator systems by Fort Huachuca, the state of Arizona, and the U.S. Army Engineer Research and Development Center, to address management concerns for desert plant communities and their associated threatened and endangered species.

INTRODUCTION: Invasive plants are considerable challenges for land managers in desert ecosystems, especially invasive grasses, which both benefit from and promote recurrences of fire, often reducing the persistence of native species and converting native plant communities to annual grasslands (Brooks and Pyke 2001). Invasive plants are capable of aggressively spreading into new habitat and monopolizing essential resources such as nutrients, water, and light, consequently out-competing native species. Impacts of invasive species on natural environments have contributed to the decline of 42 percent of federally threatened and endangered species nationwide (U.S. Environmental Protection Agency (USEPA) 2001), and following direct loss of habitat, invasive species are the next greatest threat to the survival of native species. Potential negative impacts of invasive species include the disruption of ecosystem structure and function via the alteration of community composition, the reduction of available resources, and diminished reproductive efficiency.

The genus Agave is an important native taxa to assess the effects of invasive grasses because agaves are keystone species (one whose impact on its ecosystem is disproportionately large

\footnotetext{
${ }^{1}$ U.S. Army Engineer Research and Development Center, Vicksburg, MS.

${ }^{2}$ Northern Arizona University, Flagstaff, AZ.
} 
relative to its abundance) of semiarid and arid regions of the southwest with considerable ecological and economic value (Good-Avila et al. 2006). The Palmer's agave (Agave palmeri) is state protected in Arizona and is currently threatened by the invasive African plant, Lehmann lovegrass (Eragrostis lehmanniana), as grasses strongly compete with agave seedlings (U.S. Fish and Wildlife Service (USFWS) 1999). A. palmeri grows in sandy to gravelly places on limestone in oak woodlands and grassy plains at elevations between 900-2,000 m in Arizona, New Mexico, and Mexico (Flora of North America Editorial Committee 2002). Agave plays a key role in the life history of the federally endangered lesser long-nosed bat (Leptonycteris curasoae) and state listed Mexican long-tongued bat (Choeronycteris mexicana). It is an important nectar and pollen resource for a large variety of pollinators, including bees, hummingbirds, orioles, butterflies, and wasps (National Park Service (NPS) 2007). However, little is known regarding the effect of agave on insect pollinators.

E. lehmanniana was introduced in southern Arizona in 1932 to control soil erosion and provide forage for cattle and has since spread throughout the southwest (Crider 1945; Gori and Enquist 2003; Bock et al. 2007). It is now considered a major plant species on about 140,000 hectares (ha), primarily located in southeastern Arizona (Halvorson and Guertin 2003), and has the potential to spread to over 7,000,000 ha under predicted climate change scenarios (Huang and Geiger 2008). The biomass of E. lehmanniana is typically two to four times greater than the biomass produced by native grass vegetation (Anable et al. 1992); thus, it can indirectly impact pollinators by crowding out native plants and reducing the availability of nectar sources and nesting sites (e.g. woody stems and bare earth used by bees). Currently, E. lehmanniana grows at elevations from 200-1,830 m (Flora of North America Editorial Committee 2007). The potential for E. lehmanniana to dominate and influence ecosystems is likely increasing because under changing climate conditions, its future distribution is predicted to be much greater than its current distribution (Schussman et al. 2006), with colonization spreading to areas higher in elevation and much farther north than its present range.

Additionally, the lovegrass can indirectly affect plant interactions by altering fire dynamics throughout the ecosystem. Prescribed fires to remove E. lehmanniana populations have been unsuccessful in maintaining control, often resulting in regrowth during subsequent seasons (Rogers 2004). Furthermore, the lovegrass has been shown to increase the frequency and intensity of natural fires (Kupfer and Miller 2005), which could alter A. palmeri germination, growth, abundance, and resource availability and foraging behavior of pollinators (Geiger 2006; Gucker 2006). Agave stalks are edible to wild herbivores such as deer, javelina, rodents, and rabbits (USFWS 1999). Because agave stalks often remain available following fire when other food resources are limited, herbivores may favor them, negatively impacting the availability of flowering stalks for pollinators, such as the nectar-feeding bats (USFWS 1999). In addition to the direct mortality of agave, fire may alter the availability of blooms, as agaves physiologically commit to bolt by early spring. If an agave survives a burn, bolting continues although the stalk is then smaller and has fewer flowers (Howell 1996; USFWS 1999), and if an agave stalk burns directly, the reproductive effort and the availability of nectar for that plant is completely lost (USFWS 1999). Both of these situations result in reduced availability of nectar for pollinators.

This study assesses the impacts of invasive species on key components of ecosystems and pollinator communities. To integrate aspects of invasive nonnative plant invasion with other ecological processes, the spatial effects of fire, soil type, and E. lehmanniana on the distribution and 
density of $A$. palmeri are assessed, and changes in agave pollinator community composition and diversity in the presence of high E. lehmanniana abundance are investigated. A network approach was implemented (Jordano et al. 2006; Olesen et al. 2006) to describe and analyze how agave interacts through shared pollinators with other plants, and to detect any differences in the structures of these agave "ego networks" associated with low and high E. lehmanniana abundance. Network visualization and analysis of pollination communities can provide key insights into important ecological relationships that foster species persistence, biodiversity, and community stability (Aizen et al. 2009; Carvalheiro et al. 2008; Fontaine et al. 2006; Memmott et al. 2004). The agave ego network was restricted to only those plants directly connected to A. palmeri, making other common network measures, such as diameter or closeness centrality, meaningless or redundant with other statistics. Information gained from this study will be leveraged against ongoing work on pollinator systems by Fort Huachuca, the state of Arizona, and the U.S. Army Engineer Research and Development Center, to address management concerns for desert plant communities and associated threatened and endangered species.

\section{METHODS:}

Study Locale. The study was conducted on Fort Huachuca, located in Cochise County of southeastern Arizona (Figure 1). Nearly 3,000 ha of Agave have been documented (Danzer and Roberts 2003) on the 33,000-ha installation. Fort Huachuca has well characterized vegetative communities, supports a number of rare plants and pollinators, and has a high diversity of pollinators. The overall study area (21,200 ha) did not include the northeast section of the base, as agave was not present and fire history data were not available. Study sites were selected using prior data ${ }^{1,2}$ to locate areas characterized by high ( $\geq 35$ percent) and low ( $\leq 15$ percent) abundance E. lehmanniana, and low, medium, and high densities of $A$. palmeri. These study sites were chosen in paired locations for high and low abundance E. lehmanniana over relatively homogenous terrain (elevation ranged from about $1450-1550 \mathrm{~m}$ ) to minimize environmental variance. Mean E. lehmanniana percentage was determined between two classes of study sites (high $=52.83$ percent \pm 18.37 percent, low $=5.67$ percent \pm 4.59 percent $)$ to be significantly different $\left(F_{1,11}=37.24, P=0.0001\right)$ using PROC GLM (SAS Institute 2005). Surveys and sampling were conducted during the summer of 2008.

Distribution of Eragrostis lehmanniana and Agave palmeri in Relation to Fire and Soil. Geographic information systems (GIS) data were obtained, including shapefiles of fire history from 1975-2006, soil types (Soil Survey Geographic (SSURGO)), and agave distribution and density (provided by D. Schlichting). High-resolution (1-m) 2007 color infrared imagery (USDA National Agriculture Imagery Program) was obtained for determining canopy cover of overstory tree species (e.g. Prosopis spp.). High-resolution imagery was classified using a supervised classification to differentiate areas of tree canopy from grasslands. With this imagery, the authors were able to remotely detect the presence of larger shrubs and trees (crown diameter $>1 \mathrm{~m}$ ), and quantify canopy cover.

\footnotetext{
${ }^{1}$ Personal communication. 2009. University of Arizona, Tucson, AZ.

2 Personal communication. 2009. D. Schlicting, Range Training Lands Assessment Coordinator, Colorado State University Center for Environmental Management of Military Lands, Ft. Huachuca, AZ.
} 


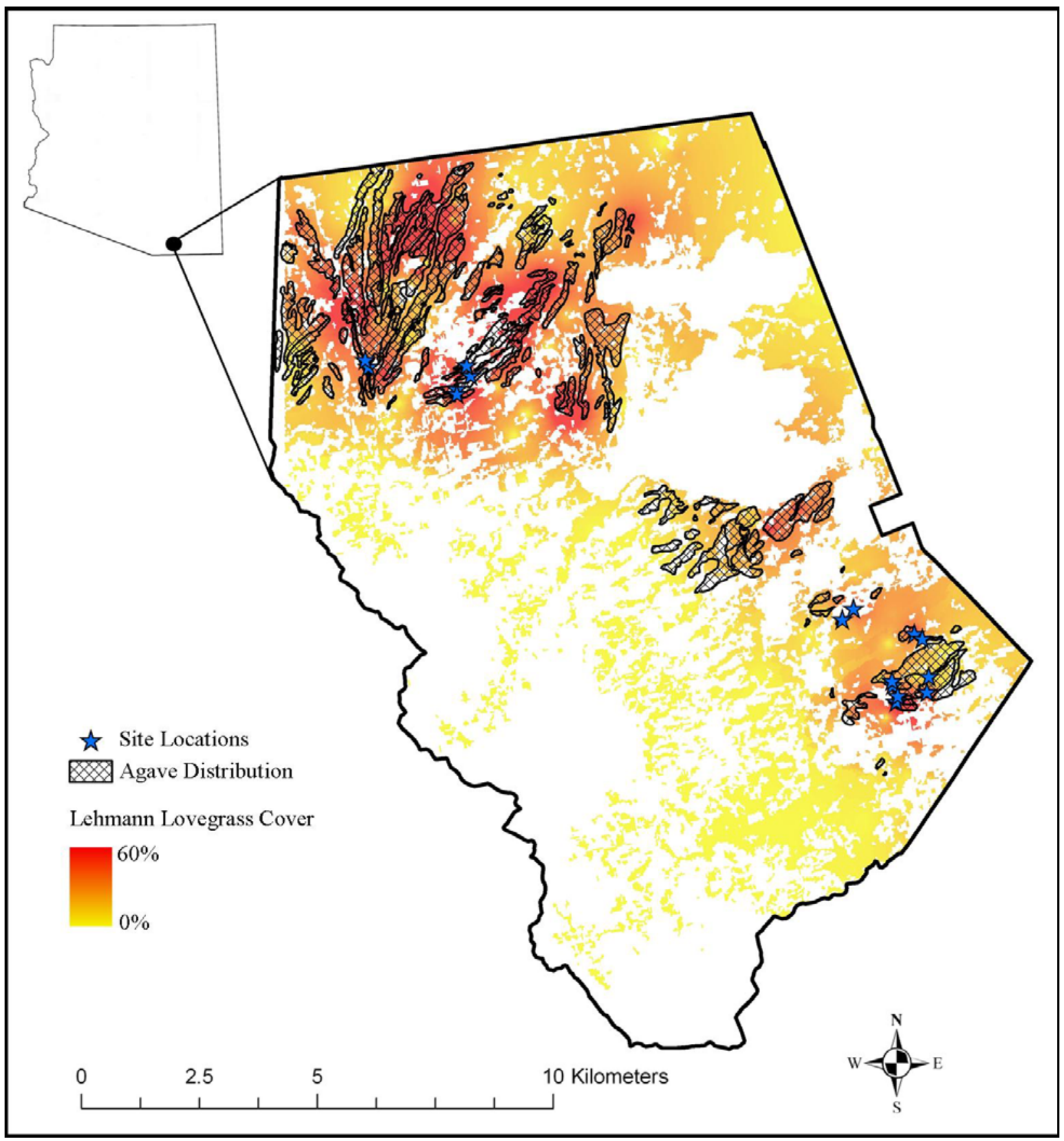

Figure 1. Map of study area and sample site locations (stars) on Fort Huachuca, Arizona, including Agave palmeri distribution (cross-hatched) and Eragrostis lehmanniana percent cover (shaded). E. lehmanniana was masked to the extent of grasslands as determined by the Southwest Regional Gap Analysis Program (SWReGAP) (Lowry et al. 2007).

Spatial analyses were performed by overlaying shapefiles and rasters to determine the interactions of spatial distributions of fire, soil-type, E. lehmanniana, and A. palmeri. To increase sampling efficiency, 1,000 random points were generated for the high, medium, and low density A. palmeri datasets (Beyer 2004). Trends in the distribution and density of A. palmeri were analyzed relative to the distribution and density of E. lehmanniana by using an inverse distance 
weighting interpolation from point data (all percent cover of E. lehmanniana) collected in 2004 and $2006^{1}$ and 2008 which occurred on the study area. The output of this interpolation was a spatial dataset of percent cover of E. lehmanniana. The relationship of E. lehmanniana density to fire occurrence was also assessed, to further investigate the effects of E. lehmanniana on A. palmeri through potential impacts to A. palmeri survival, and thus A. palmeri pollinator guilds. This was accomplished by creating 1,000 random points in the area of A. palmeri distribution (high, medium, and low) and masking the E. lehmanniana dataset to each fire occurring from 1975-2006. At each random point within each fire year, the percent cover of E. lehmanniana was compared to cover not burned during that year. An analysis of variance (ANOVA) was used to compare A. palmeri density with both fire occurrence and percent coverage of E. lehmanniana, and all significant values were accepted at the 0.05 probability level using SPSS 16.0 (SPSS, Inc. 2007).

Interpolated percent cover of E. lehmanniana was masked to the extent of grasslands as determined by the Southwest Regional Gap Analysis Program (SWReGAP; Lowry et al. 2007) and the distribution of A. palmeri was excluded. Then 1000 random points were generated that overlaid the potential E. lehmanniana distribution (e.g., grasslands and non-agave) and extracted E. lehmanniana percent cover on these points. Percent cover of E. lehmanniana was also determined by generating 1,000 random points within the distribution of A. palmeri and compared to percent E. lehmanniana in non-agave areas with an ANOVA. To determine which soil types are preferred by E. lehmanniana, 1,000 random points were generated and soil type was extracted from a SSURGO soils dataset, and percent cover was extracted from the interpolated E. lehmanniana dataset. An ANOVA was used to determine whether percent cover of E. lehmanniana differed significantly between soil types.

Agave palmeri Surveys. The relative abundance and size class of A. palmeri were quantified at each of 10 sites characterized by high $(\mathrm{N}=5)$ and low $(\mathrm{N}=5)$ E. lehmanniana abundance in the grassland vegetation community. The total number of live and dead A. palmeri were quantified per site, and size class was calculated by measuring the average diameter of each living A. palmeri using a standard measuring tape. Diameter was calculated by averaging two perpendicular measurements across the top of the plant. Comparisons of the number of live and dead A. palmeri between sites with high and low E. lehmanniana abundance were conducted with an analysis of variance using PROC GLM (SAS Institute 2005). A Kolmogorov-Smirnov test was performed to compare size class differences between high and low E. lehmanniana abundance sites using PROC NPAR1WAY (SAS Institute 2005).

Pollinator Sampling. Two related pollinator studies were conducted. The first was a directed assessment of insect pollinators visiting A. palmeri flowers. For this study, pollinators from A. palmeri were sampled during the peak agave flowering season (July and August). Once per month, pollinators were collected on blooms from 7-10 individual A. palmeri per site, at each of 12 sites characterized by high $(\mathrm{N}=6)$ and low $(\mathrm{N}=6)$ E. lehmanniana abundance. Individual agaves were systematically sampled for 2 consecutive minutes with battery-powered handheld vacuums modified for insect collection while perched on orchard ladders to reach flowering stalks that range in height from 3-6 m. Insects were identified to the lowest possible taxonomic

\footnotetext{
${ }^{1}$ Personal communication. 2009. D. Schlichting, Range Training Lands Assessment Coordinator, Colorado State University Center for Environmental Management of Military Lands, Ft. Huachuca, AZ.
} 
level. Efforts were made to observe pollination by hummingbirds on agave, but due to very few interactions and difficulties with species identification, hummingbird data were not included in the analyses. Likewise, data on nocturnal pollinators were not included.

A. palmeri pollinator community differences between high and low E. lehmanniana abundance sites were assessed by comparing mean species richness and species abundance among sites with a one-way analysis of variance using PROC ANOVA (SAS Institute 2005). Species indicator analysis was conducted with a Monte Carlo test of significance to determine whether specific pollinator taxa responded to high or low E. lehmanniana abundance. A multi-response permutation procedure (MRPP) was used to determine pollinator community composition differences between high and low E. lehmanniana abundance sites.

The second pollinator study examined plant-pollinator networks from a complementary ongoing study of all pollinators associated with grasslands on Fort Huachuca to assess networks for A. palmeri insect pollinators. For this study, 16 plots $(100 \mathrm{~m} \times 25 \mathrm{~m})$ characterized by high $(\mathrm{N}=8)$ and low $(\mathrm{N}=8)$ E. lehmanniana abundance were surveyed for pollinator-plant interactions monthly from April through September, with the exception of June. Each plot was divided into five sampling lanes, four of which were randomly selected for sampling by a randomly assigned field technician. Sampling was conducted using the same handheld vacuums used for the agave-centric pollinator sampling and focused on capturing all insects found on flowers (any species) along each of the four selected transects over a 20-minute period, with collection on individual plants limited to 2 consecutive minutes. Plots were sampled once per month, with the order of sampling both among and within plot pairs randomly assigned. Plants on each plot were identified to species and collected insects were identified to the lowest possible taxonomic level. As explained earlier, hummingbirds and nocturnal pollinator activity on plots was not recorded.

All flower-feeding Hymenoptera and Lepidoptera, and the plant species on which they were collected, were used to create rectangular weighted adjacency matrices and corresponding bipartite (or 2-mode) networks: one set for native (combined data from all low E. lehmanniana abundance sites and all months) and another set for invaded (combined data from all high E. lehmanniana abundance sites and all months). In these matrices, plant species comprise the row categories and insect pollinators the column categories, with the number of individuals of an insect species captured on a plant represented in the corresponding matrix cell. For the bipartite network, each plant and pollinator corresponds to a node, and the number of pollinators captured on a plant provides a weighting for the edges $(=$ links) between plant and pollinator nodes. To visualize and analyze the structure of plant-plant interactions (= shared pollinators), the weighted adjacency matrices were dichotomized and collapsed to create new, square weighted adjacency matrices and corresponding unipartite (or 1-mode) networks. In the new weighted adjacency matrices, the constituent plants comprise both column and row categories and the matrix cells correspond to the number of pollinator species shared by pairs of different plant species. For the unipartite network, each species of plant corresponds to a node, and the number of pollinator species shared by two plant species corresponds to a weighted edge between nodes. In order to focus analyses on A. palmeri, reduced matrices corresponding to the unipartite (1-mode) "ego networks" of agave (all plants linked directly to A. palmeri through shared pollinators) were extracted from the broader data sets. ${ }^{1}$ Because many of the available analyses can only be used

\footnotetext{
${ }^{1}$ Treatment of the full pollination network data will be presented in a separate publication.
} 
to analyze unweighted (binary) networks, the weighted agave ego network matrices were dichotomized to create unweighted adjacency matrices and corresponding unweighted unipartite networks. The significance of differences in standard network measures, described earlier, for unipartite networks from areas with high and low E. lehmanniana abundance were determined following bootstrap procedures described by Snijders and Borgatti (1999). All matrix processing and network analyses were executed using UCINET 6.0 (Borgatti et al. 1999), and network creation and visualization were executed with Pajek 1.02 (Batagelj and Mrvar 1998). Network parameters of interest (reviewed in Börner et al. 2007) included those related to topology, such as: number of nodes or size of the network $(N)$, number of edges or links $(E)$, density of the network $\left(D=\frac{2 E}{N(N-1)}\right)$ and several measures of network connectedness, including mean number of edges per node $(\bar{k})$ or mean degree centrality $\left(\overline{C_{D}}\right)$, mean betweenness centrality $\left(\overline{C_{B}}\right)$; the proportion of shortest network paths between other nodes that incorporate a node), mean eigenvector centrality $\left(\overline{C_{E}}\right.$; a measure of the degree to which a node is a component of overall connectedness in the network), and mean Bonacich power $\left(\overline{C_{\beta}}\right.$; when the attenuation factor, $\beta$, is positive, power is a positive function of being connected to well-connected nodes). Network creation and visualization were executed with Netdraw 2.085 (Borgatti 2002), with random positioning of nodes and strength of weighted edges (number of shared pollinators) represented by scaled line thicknesses (stronger edge $=$ thicker line).

\section{RESULTS:}

Agave palmeri and Eragrostis Iehmanniana distributions. A. palmeri was present in 1837 ha across the study area (21,200 ha; Figure 1), with an estimated 249 ha being designated as high density, 993 ha designated as medium density, and 595 ha designated as low density. The overall agave distribution grew with a mean of 25.7 percent E. lehmanniana cover, while mean E. lehmanniana cover in the study area was 7.3 percent \pm 0.3 percent. Although the presence of high E. lehmanniana abundance did not significantly alter the number of live $\left(F_{1,9}=0.71\right.$, $P=0.4231)$ or dead $\left(F_{1,9}=2.38, P=0.1615\right)$ A. palmeri among the sample sites, areas of low density agave had significantly higher percent coverage of E. lehmanniana than either mediumor high-density areas of agave across the study area $(F=42.50, P<0.0001$; Figure 2$)$. Additionally, a significantly higher ratio of smaller agave plants $(\leq 0.4 \mathrm{~m}$ radius $)$ to larger agave plants ( $>0.4 \mathrm{~m}$ radius) was found in sites corresponding to high E. lehmanniana abundance $(K S a=1.9578, P=0.0009)$. Overall, $A$. palmeri plants ranged in size from $0.03-2.64 \mathrm{~m}$ in diameter.

There were several fundamental differences among levels of agave density. Percent canopy cover of overstory trees was highest (1.9 percent) in high-density agave areas and lowest (1.0 percent) in low-density agave areas. Agave density also varied by the relative abundance of soil type. High density agave was largely (76.0 percent) found on the Terrarossa-Blacktail-Pyeatt Complex, while low-density agave was found equally on the Terrarossa Complex and White House Complex (Table 1). Soil type also influenced percent cover of E. lehmanniana on Fort Huachuca. Aside from the Ubik Complex, the three most common soil types where agave was found (Terrarossa-Blacktail-Pyeatt Complex, Terrarossa Complex, and White House Complex) had the most E. lehmanniana cover of any soil type (13-19 percent; Table 1). Percent cover of 
E. lehmanniana was significantly higher $(F=398.33, P<0.001)$ within the distribution of agave than in non-agave areas (Figure 3).

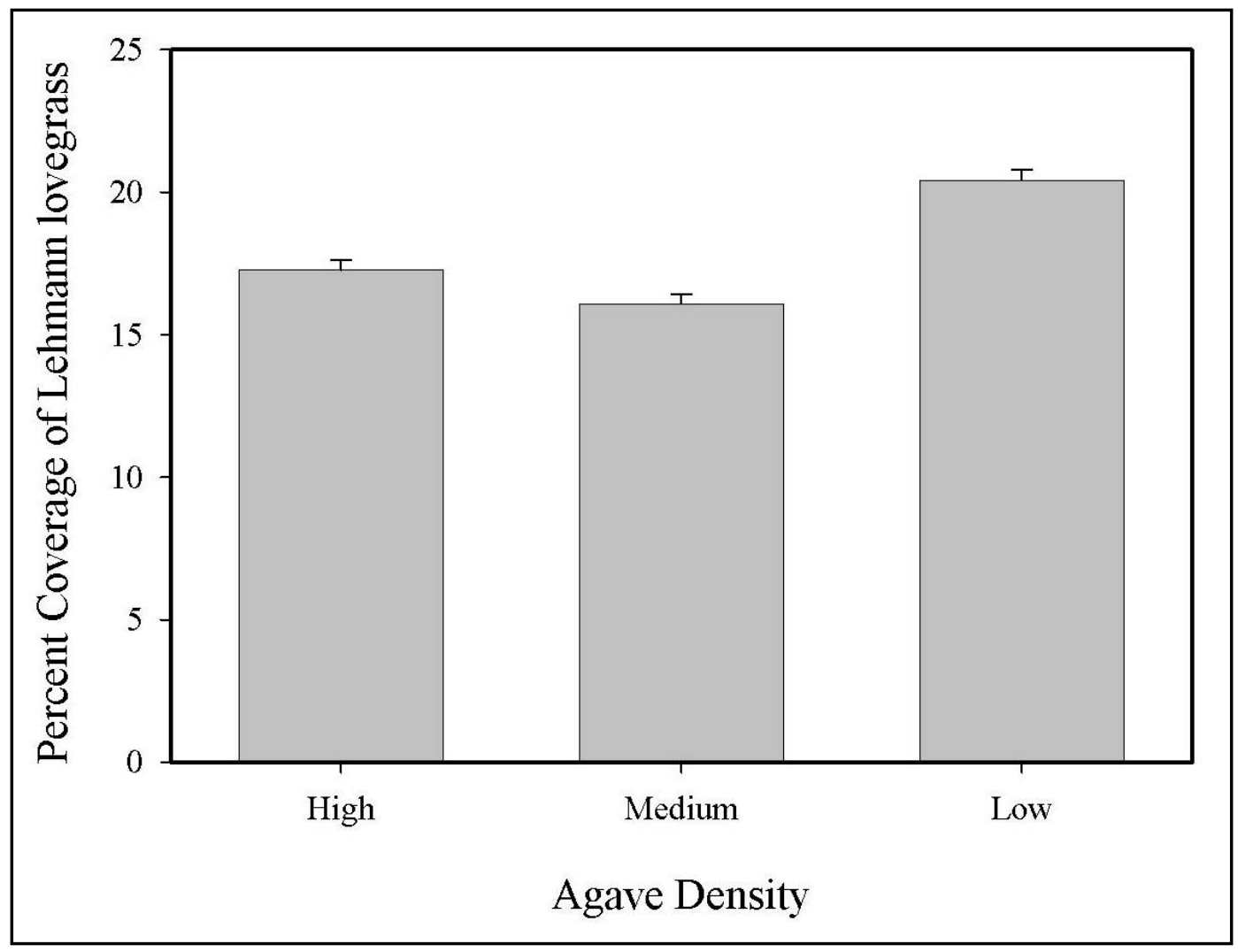

Figure 2. Low-density Agave palmeri corresponds to significantly higher percent coverage of Eragrostis lehmanniana than either medium- or high-density agave $(F=42.50, P<0.0001)$.

\section{Table 1. Influence of soil type on Agave palmeri distribution and Eragrostis lehmanniana abundance. ${ }^{1}$}

\begin{tabular}{|c|c|c|c|c|c|}
\hline \multirow[b]{2}{*}{ Soil Type } & \multirow{2}{*}{$\begin{array}{l}\text { Mean } \pm \text { SD } \\
\text { Eragrostis lehmanniana } \\
\text { Percent Cover }\end{array}$} & \multicolumn{3}{|c|}{$\begin{array}{l}\text { Percent Soil Abundance of } \\
\text { Agave palmeri Distribution }\end{array}$} & \multirow{2}{*}{$\begin{array}{l}\text { Amount of } \\
\text { Landscape } \\
\text { Comprised of by } \\
\text { Soil Type }\end{array}$} \\
\hline & & \begin{tabular}{|l|} 
High \\
Density
\end{tabular} & \begin{tabular}{|l|} 
Medium \\
Density
\end{tabular} & \begin{tabular}{|l|} 
Low \\
Density
\end{tabular} & \\
\hline White House Complex & $10.9 \pm 0.7$ & 4.3 & 21.2 & 30.3 & 14.7 \\
\hline Terrarossa Complex & $11.8 \pm 0.6$ & 11.7 & 21.6 & 30.6 & 12.6 \\
\hline Budlamp-Woodcutter Complex & $3.2 \pm 0.4$ & 0.00 & 5.4 & 0.6 & 12.1 \\
\hline Far-Hogris Asscociation & $1.8 \pm 0.3$ & 0.00 & 0.00 & 0.00 & 11.5 \\
\hline Gardencan-Lanque Complex & $10.0 \pm 0.7$ & 1.8 & 3.6 & 6.5 & 10.2 \\
\hline Terrarossa-Blacktail-Pyeatt Complex & $19.1 \pm 0.9$ & 76.1 & 37.4 & 24.7 & 8.00 \\
\hline Ubik Complex & $14.7 \pm 2.7$ & 0.00 & 0.1 & 0.3 & 1.4 \\
\hline Carbine Very Gravelly Loam & $7.8 \pm 1.3$ & 5.2 & 9.8 & 4.5 & 1.3 \\
\hline
\end{tabular}




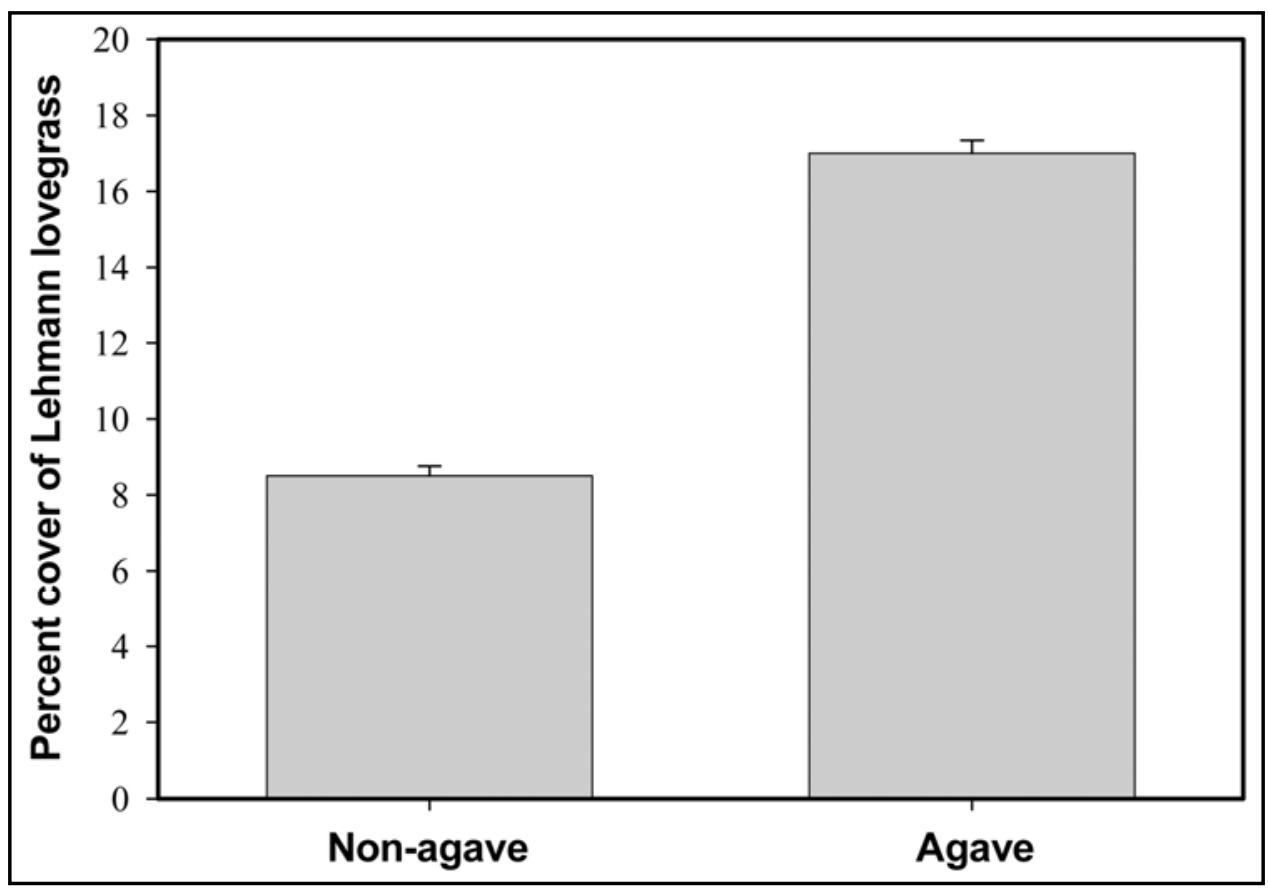

Figure 3. Eragrostis lehmanniana exhibits significantly higher percent cover in areas where Agave palmeri occurs compared to areas with no agave $(F=398.33, P<0.001)$.

Interactions of natural and prescribed burn history with E. lehmanniana distribution and density showed no discernible pattern. Areas with high E. lehmanniana abundance did not burn more frequently than areas of low E. lehmanniana abundance. For A. palmeri, however, areas of high and medium density were significantly associated with more frequent burning $(F=3.26$, $P<0.05$; Figure 4).

Pollinator Community Analysis. There was no significant difference in pollinator species richness $\left(F_{1,23}=0.14, P=0.7076\right)$ or species abundance $\left(F_{1,23}=0.50, P=0.4868\right)$ between sites with high and low E. lehmanniana abundance (Table 2). Pollinator community composition analysis revealed no significant differences between high and low E. lehmanniana abundance sites $(r=-0.015, P=0.726)$. Of the 70 taxa identified (Appendix A), only one species was an indicator of either high or low E. lehmanniana abundance; with a mean observed indicator value of $20.8 \pm 3.67$, Agapostemon angelicus was found to be an indicator species of A. palmeri located in high E. lehmanniana abundance sites $(P=0.0472)$. 


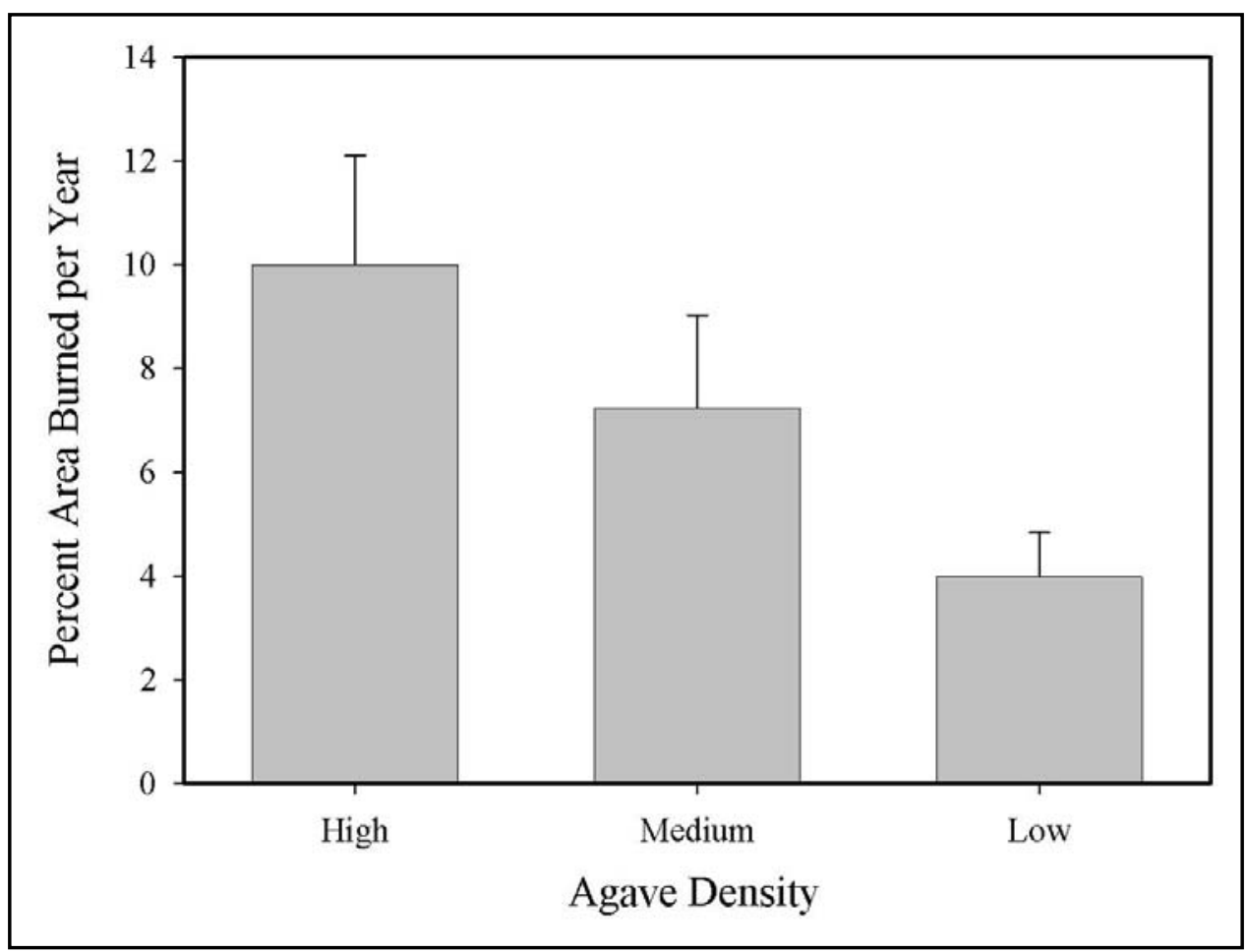

Figure 4. Agave palmeri density significantly decreases with increasing percentage of area burned per year $(F=3.26, P<0.05)$.

Table 2. Pollinator species richness and species abundance for eight high (>35 percent) and eight low (<15 percent) Eragrostiis lehmanniana abundance sites.

\begin{tabular}{||l|l|l|l|l|l||}
\hline \multirow{2}{*}{ Eragrostis lehmanniana Abundance } & \multirow{2}{*}{$\boldsymbol{n}$} & \multicolumn{2}{|c|}{ Species Richness } & \multicolumn{2}{|c|}{ Species Abundance } \\
\cline { 4 - 8 } & & Mean & SE & Mean & SE \\
\hline \hline High & 8 & 11.45 & 1.52 & 53.27 & 7.84 \\
\hline Low & 8 & 12.23 & 1.37 & 67.54 & 17.28 \\
\hline
\end{tabular}

Pollinator Network Analyses. In each agave ego network (native vs. invaded), agave was directly linked (shared $\geq 1$ pollinators) with 11 other plants (Figure 5). In addition to A. palmeri, however, the two networks only have three plant species in common, including Acacia augustissima, Calliandra eriophylla, and Prosopis velutina. The native network included 30 different insect pollinators, while the invaded network contained 14 different insect pollinators. Nine species of pollinators, Apis melifera, Dialictus microlepoides, Hemiargus isola, Microclepi spp., Bruchophagus spp., Myrmecosystus spp., Crematogaster spp., Lydella radicus, and Trupanea spp. were found within the agave ego networks in both native and invaded plots. In both of the larger community networks, the agave ego network played an important role, comprising 40 percent of the plant species. However, there were notable differences between the native and invaded agave ego networks, including a higher degree of pollinator sharing among plants in the native network relative to the invaded network $(E=92$ vs. $72 ; D=63.64$ percent vs. 43.64 percent). Significant differences (one-tailed t-tests, 10,000 bootstraps) between the unweighted unipartite networks (native vs. invaded, p-value) included mean node degree 
centrality $\left(\overline{C_{D}}=7.667\right.$ vs. $\left.5.833, p=0.041\right) \quad$ and mean node power $\left(\overline{C_{\beta}}=1160.109\right.$ vs. $\left.662.263, p>0.001\right)$. In regards to the weighted unipartite networks, the same trends hold true with $\overline{C_{D}}(14.500$ vs. $8.500, p=0.010), \overline{C_{B}}(22.792$ vs. $2.583, p=0.034)$, and mean cluster coefficient $(\bar{c}=1.821$ vs. $1.213, p=0.002)$. There were no significant differences in betweenness centrality $\left(\overline{C_{B}}=1.667\right.$ vs. $\left.2.583, p=0.653\right) \quad$ or $\quad$ eigenvector centrality $\left(\overline{C_{E}}=0.280\right.$ vs. $\left.0.276, p=0.910\right)$ for the unweighted networks, nor in eigenvector centrality for the weighted networks $\left(\overline{C_{E}}=0.268\right.$ vs. $\left.0.246, p=0.697\right)$. Agave also appears to play a more central role in the native ego network as indicated by a higher two-step reach (the percentage of other nodes within two-links of agave; 93.10 percent versus 86.21 percent).

DISCUSSION: High abundance of E. lehmanniana significantly altered the distribution of A. palmeri size classes, resulting in a higher ratio of small to large plants. Areas with a higher ratio of small to large agave plants are a management concern on Fort Huachuca because stands of small plants are considered to be important future nectar-feeding centers, and should thus be protected. ${ }^{1}$ However, areas of low-density agave had significantly higher percent coverage of E. lehmanniana than either medium- or high-density areas of agave, indicating that high E. lehmanniana abundance tends to exclude A. palmeri. Although the small/young agave plants are important, the more dense stands of agave also need to be protected, as total amount of nectar produced is the main conservation concern for the endangered lesser long-nosed bat.

Although Kupfer and Miller (2005) found that the presence of E. lehmanniana increases both the frequency and intensity of natural fires, Geiger (2006) determined that the proportion of E. lehmanniana does not increase following burns. Similarly, it was determined that areas with high E. lehmanniana abundance did not burn more frequently than areas of low E. lehmanniana abundance. However, fires did occur significantly more in areas of high-density agave than in areas of low-density agave. Because fire has the potential to reduce or eliminate agave bloom production by damaging or destroying plants, this could have a negative effect on overall nectar availability. Agave density also varied by soil type, with high-density agave being associated with the Terrarossa-Blacktail-Pyeatt Complex, also following an observation of Geiger (2006) that survival of agave varies with soil type. Because E. lehmanniana was preferentially found on the same three soil types where A. palmeri most commonly occurred, and percent cover of E. lehmanniana was significantly higher within agave areas, the two species will likely be in close association for the foreseeable future. This suggests that areas of agave may be more prone to invasion by E. lehmanniana than areas without agave.

\footnotetext{
${ }^{1}$ Personal communication. 2009. D. Schlichting, Range Training Lands Assessment Coordinator, Colorado State University Center for Environmental Management of Military Lands, Ft. Huachuca, AZ.
} 

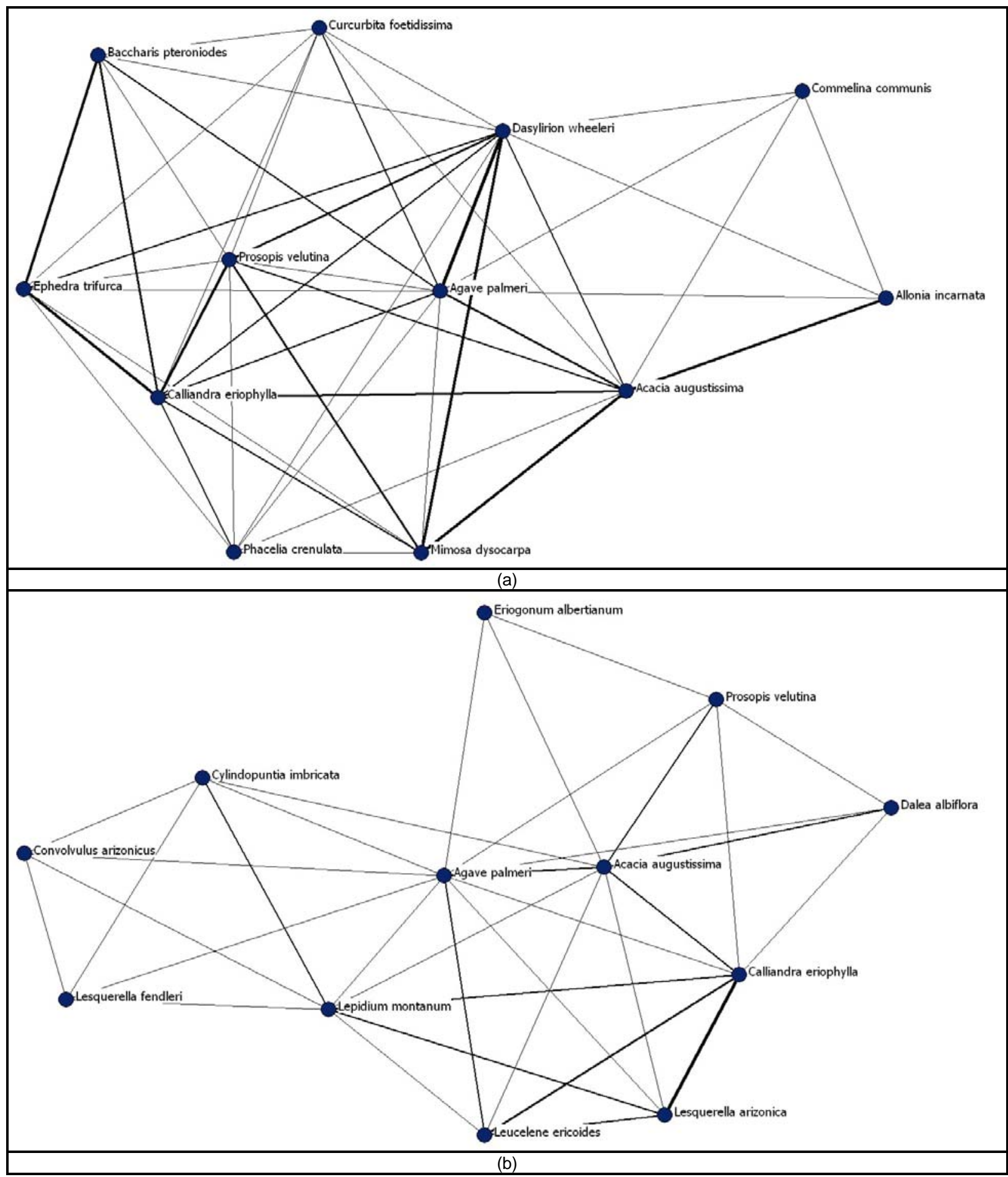

Figure 5. Unipartite networks of plants linked through shared pollinator species from a) native grass dominated plots, and b) invaded plots dominated by the nonnative grass Eragrostis lehmanianna. Line thickness reflects edge weighting (number of pollinator species shared). 
There was no significant difference in A. palmeri pollinator species richness, species abundance, or community composition between sites with high and low E. lehmanniana abundance, suggesting that E. lehmanniana does not have a negative influence on the agave pollinator guild. Agave flowering stalks often tower over the maximum height of E. lehmanniana, thus allowing pollinators to access agave blooms with ease. High E. lehmanniana abundance is concomitant with low densities of A. palmeri, which suggests that pollinator activity should also follow this pattern. However, sites with high E. lehmanniana abundance could be outcompeting other native flora, thus increasing the amount of pollinator activity on the limited numbers of A. palmeri in high E. lehmanniana abundance sites. Agapostemon angelicus, a native, pollen-feeding sweat bee, was the only pollinator observed to be an indicator species of A. palmeri in high E. lehmanniana abundance sites. The sweat bees are considered generalist species, pollinating a wide variety of flower species. Though A. angelicus could be utilizing A. palmeri as a major pollen source, the association may be due to E. lehmanniana providing cover or nesting material for A. A. angelicus; however, that may be unlikely considering that Agapostemon spp. nest in ground burrows (Michener 2000). In general, bees are the most common pollinator, a trend also observed in this study. A. palmeri pollinators collected in this study included 30 species of Hymenoptera (bees), 21 species of Diptera (flies), 9 species of Coleoptera (beetles), 4 species of Lepidoptera (butterflies), and 2 species of Hemiptera (aphids, leafhoppers, and cicadas). Two species of Coleoptera and two species of Araneae (spiders) that were herbivores or predators were also collected.

Network descriptions of the interconnectedness and co-reliance among plants that share pollinators provide potentially important insights into the combined community's robustness and resilience to changes in composition, such as loss of species (Aizen et al. 2009; Fontaine et al. 2006; Memmott et al. 2004). Network approaches also provide important insights into the role of a particular species, plant or pollinator, in supporting community structure, as well as that species' susceptibility to extinction within the community (Carvalheiro et al. 2008). In the case of agave in the Sonoran desert grassland community that was studied, it appears that A. palmeri and its one-step ego network (the plants to which it is directly linked through shared pollinators) are major components of the overall community pollinator network and likely lend a large degree of stability to the community pollination dynamics. It also appears that $A$. palmeri and the plants in its ego network are well established and supported by multiple pollinator linkages, but appear to be significantly more linked within the native network. One possible reason for the apparent greater connectedness of the native agave ego network may be a rarefaction bias in the sampling results arising from the higher density of agave in native habitat and concomitant higher probability of detecting more pollinator species. Percent cover of agave was significantly higher within native sites $(F=4.88, P=0.0444)$. In the sampling component of this study for the directed assessment of $A$. palmeri insect pollinators, where numbers of agave sampled in native and invaded habitat were equivalent, significant differences in pollinator diversity did not exist. An additional factor could be different portions of plants in the low and high E. lehmanniana abundance sites that are pollinator generalists, or pollinators that are flower generalists.

CONCLUSIONS: The nonnative grass E. lehmanniana has negatively impacted the native plant A. palmeri, which is an important resource for many pollinators in the desert communities of the Southwestern United States. E. lehmanniana may exclude A. palmeri, as areas of high E. lehmanniana abundance were associated with significantly lower densities of A. palmeri, greater numbers of small/young A. palmeri plants, and lower pollinator network connectedness. 
Although E. lehmanniana abundance had no significant effect on fire frequency, medium- and high-density A. palmeri areas were associated with increased fire frequency, which can decrease overall nectar production through direct or indirect means. Due to similar soil preferences, E. lehmanniana and A. palmeri are likely to continue be found in close association; therefore, continued study and monitoring of the invasion and impacts of E. lehmanniana on these desert communities and their associated threatened and endangered species would benefit future management decisions.

POINTS OF CONTACT: For additional information, contact Denise Lindsay (601-634-2362, denise.l.lindsay@usace.army.mil), Pamela Bailey(601-634-2380,pamela.bailey@usace.army. mil), or Dr. Richard Lance (601-634-3791, richard.f.lance@usace.army.mil). This technical note should be cited as follows:

Lindsay, D. L., P. Bailey, R. F. Lance, M. J. Clifford, R. Delph, and N. S. Cobb. 2010. Effects of a nonnative, invasive lovegrass on Agave palmeri distribution, abundance, and insect pollinator communities. ERDC/EL TN-10-1. Vicksburg, MS: U.S. Army Engineer Research and Development Center.

ACKNOWLEDGEMENTS: The authors thank Sheridan Stone, Dean Schlichting, Pamela Landin, Susan Langley, Gwynne Pollard, and John-Paul Hodnett for their assistance with field efforts and data accumulation. Funding for this project was provided by the Department of Defense Legacy Resource Management Program (MIPR: W31RYO80857494). The study described and the resulting data presented herein, unless otherwise noted, were partly obtained from research conducted under the U.S. Army Environmental Quality Technology Program by the U.S. Army Engineer Research and Development Center. Permission was granted by the Chief of Engineers to publish this information. The views expressed in this manuscript are those of the authors and do not reflect the official policy or position of the Department of the Army, Department of Defense, or the U.S. Government. The use of trade, product, or firm names in this report is for descriptive purposes only and does not imply endorsement by the U.S. Government.

\section{REFERENCES:}

Aizen, M. A., C. L. Morales, and J. M. Morales. 2009. Invasive mutualists erode native pollination webs. PLoS Biology 6:e31.

Anable, M. E., M. P. McClaran, and G. B. Ruyle. 1992. Spread of introduced Lehmann lovegrass Eragrostis lehmanniana Nees. in southern Arizona, USA. Biological Conservation 61:181-188.

Batagelj, V., and A. Mrvar. 1998. Pajek: Program for large network analysis. Connections 21:47-57.

Beyer, H. L. 2004. Hawth's analysis tools for ArcGIS. http://www.spatialecology.com/htools.

Bock, C. E., J. H. Bock, L. Kennedy, and Z. F. Jones. 2007. Spread of non-native grasses into grazed versus ungrazed desert grasslands. Journal of Arid Environments 71:229-235.

Borgatti, S. P., M. G. Everett, and L. C. Freeman. 1999. UCINET 6.0 Version 1.00. Natick: Analytic Technologies.

Borgatti, S. P. 2002. NetDraw: Graph Visualization Software. Harvard, MA: Analytic Technologies. 
Börner, K., S. Sanyal, and A. Vespignani. 2007. Network science. In Annual review of information science and technology, V.41, ed. B Cronin, 12:537-607. Medford, NJ: Information Today, Inc./American Society for Information Science and Technology.

Brooks, M. L., and D. A. Pyke. 2001. Invasive plants and fire in the deserts of North America. In Proceedings of the Invasive Species Workshop - the Role of Fire in the Control and Spread of Invasive Species, ed. K.E.M. Galley and T.P. Wilson, 1-14. Tallahassee, FL: Fire Conference 2000 - the First National Congress on Fire Ecology, Prevention, and Management. Miscellaneous Publication No. 11, Tall Timbers Research Station.

Carvalheiro, L. G., E. R. M. Barbosa, and J. Memmott. 2008. Pollinator networks, alien species, and the conservation of rare plants: Trinia glauca as a case study. Journal of Applied Ecology 45:1419-1427.

Crider, F. J. 1945. Three introduced lovegrasses for soil conservation. Washington, DC: U.S. Government Printing Office, U.S. Department of Agriculture Circular.

Danzer, S., and J. Roberts. 2003. Monitoring Palmer's Agave (Agave palmeri) on Fort Huachuca, Arizona: 2002 Monitoring Report.

Flora of North America Editorial Committee. 2002. Flora of North America, Volume 26. New York: Oxford University Press.

Flora of North America Editorial Committee. 2007. Flora of North America, Volume 25. New York: Oxford University Press.

Fontaine, C., I. Dajoz, J. Meriguet, and M. Loreau. 2006. Functional diversity of plant-pollinator interaction webs enhances the persistence of plant communities. PLoS Biology 4:e1.

Geiger, E. L. 2006. The role of fire and a nonnative grass as disturbances in semi-desert grasslands of southeastern Arizona. PhD diss., School of Renewable Natural Resources, University of Arizona.

Good-Avila, S. V., V. Souza, B. S. Gaut, and L. E. Eguiarte. 2006. Timing and rate of speciation in Agave (Agavaceae). PNAS 103: 9124-912.

Gori, D. F., and C. A. F. Enquist. 2003. An assessment of the spatial extent and condition of grasslands in central and southern Arizona, southwestern New Mexico and northern Mexico. Tucson, AZ: The Nature Conservancy, Arizona Chapter.

Gucker, C. L. 2006. Agave lechuguilla. In Fire Effects Information System. U.S. Department of Agriculture, Forest Service, Rocky Mountain Research Station, Fire Sciences Laboratory. http://www.fs.fed. us/database/feis/

Halvorson, W. L., and P. Guertin. 2003. Factsheet for Eragrostis lehmanniana Nees. USGS Weeds in the West project: Status of Introduced Plants in Southern Arizona Parks.

Howell, D. J. 1996. Agave palmeri on Fort Huachuca: Five years of research on natural history and response to fire. Report to Fort Huachuca, AZ.

Huang, C., and E. L. Geiger. 2008. Climate anomalies provide opportunities for large-scale mapping of non-native plant abundance in desert grasslands. Diversity and Distributions 14:875-884. 
Jordano, P., J. Bascompte, and J. M. Olesen. 2006. The ecological consequences of complex topology and nested structure in pollination webs. In Specialization and generalization in plant-pollinator interactions, ed. N.M. Waser and J. Ollerton, 173-199. University of Chicago Press, EEUU.

Kupfer, J. A., and J. D. Miller. 2005. Wildfire effects and post-fire responses of an invasive mesquite population the interactive importance of grazing and non-native herbaceous species invasion. Journal of Biogeography 32:453-466.

Lowry, J. H., Jr., R. D. Ramsey, and K. A. Thomas, et al. 2007. Land cover classification and mapping. Chapter 2. In Southwest Regional Gap Analysis Final Report, ed. J.S. Prior-Magee, et al. Moscow, ID: U.S. Geological Survey, Gap Analysis Program.

Memmott, J., N. Waser, and M. Price. 2004. Resilience of pollination networks to species extinctions. Proceedings of the Royal Society, B 271:2605-2611.

Michener, C. D. 2000. The bees of the world. Baltimore, MD: Johns Hopkins University Press.

National Park Service (NPS). 2007. Coronado National Memorial. http://www.nps.gov/archive/coro/ pphtml/10highlights354.html.

Olesen, J. M., J. Bascompte, Y. L. Dupont, and P. Jordano. 2006. The smallest of worlds: Pollination network. Journal of Theoretical Biology 240:270-276.

Rogers, K. 2004. Lehmann lovegrass won't succumb to fire. University of Arizona News Services.

SAS Institute. 2005. SAS Onlinedoc 9.1.3. Cary, NC: SAS Institute Inc.

Schussman, H., E. Geiger, T. Mau-Crimmins, and J. Ward. 2006. Spread and current potential distribution of an alien grass, Eragrostis lehmanniana Nees, in the southwestern USA: comparing historical data and ecological niche models. Diversity and Distributions 12:582-592.

Snijders, T. A. B., and S. P. Borgatti. 1999. Non-parametric standard errors and tests for network statistics. Connections 22:61-70.

Soil Survey Geographic (SSURGO) Database for [Pima and Cochise County, Arizona]. Available online at http://soildatamart.nrcs.usda.gov.

SPSS, Inc. 2007. SPSS for Windows, Version 16.0. Chicago, IL.

U.S. Environmental Protection Agency (USEPA). 2001. Nonindigenous species - An emerging issue for the EPA. http://www.epa.gov/owow/invasive_species/workshop/nisvol1.pdf.

U.S. Fish and Wildlife Service (USFWS). 1999. Biological opinion on activities on Fort Huachuca Military Reservation, 2-21-98-F-266. October 27, 1999.

NOTE: The contents of this technical note are not to be used for advertising, publication, or promotional purposes. Citation of trade names does not constitute an official endorsement or approval of the use of such products. 


\section{Appendix A. Agave palmeri pollinator species list grouped by feeding guild.}

\begin{tabular}{|c|c|c|c|}
\hline Guild & Order & Family & Genus and Species \\
\hline pollen-feeder & Hymenoptera & Andrenidae & Perdita albovittata \\
\hline pollen-feeder & Hymenoptera & Andrenidae & Perdita spp. \\
\hline pollen-feeder & Hymenoptera & Anthophoridae & Diadasia rinconis \\
\hline pollen-feeder & Hymenoptera & Apidae & Apis melifera \\
\hline pollen-feeder & Hymenoptera & Apidae & Bombus sonorus \\
\hline pollen-feeder & Hymenoptera & Apidae & Xylocopa californica \\
\hline pollen-feeder & Hymenoptera & Colletidae & Colletis spp. \\
\hline pollen-feeder & Hymenoptera & Colletidae & Ptiloglossa arizonensis \\
\hline pollen-feeder & Hymenoptera & Halictidae & Agapostemon angelicus \\
\hline pollen-feeder & Hymenoptera & Halictidae & Dialictus comulus \\
\hline pollen-feeder & Hymenoptera & Halictidae & Dialictus microlepoides \\
\hline pollen-feeder & Hymenoptera & Halictidae & Dialictus pruinosiformis \\
\hline pollen-feeder & Hymenoptera & Halictidae & Dialictus spp. 1 \\
\hline pollen-feeder & Hymenoptera & Halictidae & Dialictus spp. 2 \\
\hline pollen-feeder & Hymenoptera & Halictidae & Halictus tripartitus \\
\hline pollen-feeder & Hymenoptera & Halictidae & Sphecodes stygius \\
\hline pollen-feeder & Hymenoptera & Megachilidae & Lithurgus apicalis \\
\hline pollen-feeder & Hymenoptera & Halictidae & unknown \\
\hline nectar-feeder & Lepidoptera & Lycanidae & Timolus azia \\
\hline nectar-feeder & Lepidoptera & Lycanidae & Leptotes marina \\
\hline nectar-feeder & Lepidoptera & Sphingidae & Hyles lineata \\
\hline nectar-feeder & Lepidoptera & Zygaenidae & Ctenucha venosa \\
\hline nectar/herbivore & Diptera & Sepsidae & unknown \\
\hline nectar/herbivore & Diptera & Otitidae & unknown 1 \\
\hline nectar/herbivore & Diptera & Otitidae & unknown 2 \\
\hline nectar/herbivore & Diptera & Lonchaeidae & Lonchaea spp. \\
\hline nectar/herbivore & Diptera & Sciaridae & unknown \\
\hline nectar/herbivore & Diptera & Chloropidae & unknown \\
\hline nectar/herbivore & Diptera & Chloropidae & Thaumatomyia spp. \\
\hline nectar/herbivore & Diptera & Phoridae & unknown \\
\hline nectar/herbivore & Diptera & Anthomyiidae & unknown 1 \\
\hline nectar/herbivore & Diptera & Anthomyiidae & unknown 2 \\
\hline nectar/herbivore & Diptera & Anthomyiidae & unknown 3 \\
\hline nectar/herbivore & Diptera & Sarcophagidae & Sarcophaga spp. \\
\hline nectar/herbivore & Diptera & Sarcophagidae & unknown \\
\hline nectar/herbivore & Diptera & Caliphoridae & Phaenicia spp. \\
\hline nectar/herbivore & Coleoptera & Cleridae & Enoclerus abdominalis \\
\hline nectar/herbivore & Coleoptera & Scarabaeidae & Cotinus texana arizonica \\
\hline nectar/herbivore & Coleoptera & Scarabaeidae & Euphoria testacea \\
\hline nectar/herbivore & Coleoptera & Lycidae & Lycus sanguineus \\
\hline nectar/herbivore & Coleoptera & Bruchidae & unknown 1 \\
\hline nectar/herbivore & Coleoptera & Bruchidae & unknown 2 \\
\hline nectar/herbivore & Coleoptera & Curculionidae & Apion spp. \\
\hline nectar/herbivore & Coleoptera & Curculionidae & Peltophorus polymitus \\
\hline nectar/herbivore & Coleoptera & Mordellidae & unknown \\
\hline
\end{tabular}


ERDC/EL TN-10-1

May 2010

\begin{tabular}{|c|c|c|c|}
\hline Guild & Order & Family & Genus and Species \\
\hline nectar/herbivore & Hemiptera & Coreidae & Acanthocephala thomasi \\
\hline nectar/predator & Hymenoptera & Scolitidae & unknown \\
\hline nectar/predator & Hymenoptera & Vespidae & Polistes castanelcolor \\
\hline nectar/predator & Hymenoptera & Vespidae & Polistes fuscatus \\
\hline nectar/predator & Hymenoptera & Vespidae & Eumenes bollii \\
\hline nectar/predator & Hymenoptera & Tiphiidae & Tiphia spp. \\
\hline nectar/predator & Hymenoptera & Bethyliidae & unknown \\
\hline nectar/predator & Hymenoptera & Braconidae & Bruchophagus spp. 1 \\
\hline nectar/predator & Hymenoptera & Braconidae & Bruchophagus spp. 2 \\
\hline nectar/predator & Hymenoptera & Braconidae & unknown 1 \\
\hline nectar/predator & Hymenoptera & Braconidae & unknown 2 \\
\hline nectar/predator & Hymenoptera & Braconidae & unknown 3 \\
\hline nectar/predator & Hymenoptera & Eulophidae & unknown \\
\hline nectar/predator & Diptera & Tachinidae & Juriniopsis adusta \\
\hline nectar/predator & Diptera & Tachinidae & Lydella radicus \\
\hline nectar/predator & Diptera & Tachinidae & unknown 1 \\
\hline nectar/predator & Diptera & Tachinidae & unknown 2 \\
\hline nectar/predator & Diptera & Syrphidae & Eristalis tenax \\
\hline nectar/predator & Diptera & Syrphidae & Neocnemodon sp. \\
\hline nectar/predator & Diptera & Conopidae & Conops sp. \\
\hline nectar/predator & Hemiptera & Anthocoridae & Orius insidiosus \\
\hline herbivore & Coleoptera & Chrysomelidae & Zygospila continua \\
\hline predator & Coleoptera & Carabidae & unknown \\
\hline predator & Araneae & Thomisidae & Misumena vatia \\
\hline predator & Araneae & Salticidae & unknown \\
\hline
\end{tabular}

